\title{
Acute upper airway obstruction due to retropharyngeal hematoma in a dog with Anaplasma species: a case study
}

\author{
Verónica Vieitez ${ }^{*}$ María Martín-Cuervo, Víctor López-Ramis and Luis Javier Ezquerra
}

\begin{abstract}
Background: Retropharyngeal hematoma is a rare condition that is difficult to diagnose and may progress rapidly to airway obstruction. The authors report the first known case of acute upper airway obstruction resulting from retropharyngeal hematoma in a dog. Documented causes in human medicine have included coagulopathic states, trauma, infection, parathyroid adenoma rupture, and foreign body ingestion. Vague symptoms in humans such as sore throat, shortness of breath, dysphonia, dysphagia, and neck swelling may precede lethal airway obstruction.
\end{abstract}

Case presentation: The authors report a case of an 18-month-old, intact female water spaniel with thrombocytopenia that developed a massive retropharyngeal hematoma and symptoms of airway compromise. The dog required tracheal intubation followed by surgical tracheostomy. Lateral cervical radiography and magnetic resonance imaging of the neck was consistent with a retropharyngeal hematoma compromising the airway. The retropharyngeal hematoma was managed conservatively.

Conclusion: Retropharyngeal hematoma should be considered in patients presenting with abrupt respiratory distress. Magnetic resonance imaging allowed specific diagnosis of a rare condition that is otherwise difficult to diagnose.

Keywords: Canine, Bleeding disorders, Acute airway obstruction, Retropharyngeal hematoma

\section{Background}

Retropharyngeal hematoma $(\mathrm{RH})$ is a rare condition that can rapidly cause airway obstruction in people $[1,2]$. The condition develops when blood collects in the retropharyngeal space, which extends from the base of the skull cranially to the level of the tracheal bifurcation caudally and therefore, provides a route for communication between the neck and the chest [3]. The retropharyngeal space itself contains lymph nodes, fat, and lymphatic channels, but no great vessels or organs [4].

The clinical presentations of RH differ depending on the size of the $\mathrm{RH}$ and its rate of growth. $\mathrm{RH}$ is characterized by the clinical triad of tracheal and esophageal compression, ventral tracheal displacement, and the subsequent appearance of subcutaneous bruising in the anterior neck and upper thorax [5]. Sore throat, shortness of breath, dysphagia and odynophagia, either alone or in various

\footnotetext{
*Correspondence: vvieitez@gmail.com

Veterinary Teaching Hospital, University of Extremadura, Avda, Universidad s/n, Cáceres 10003, Spain
}

combinations, may be the initial symptoms. Bruising, tenderness and/or swelling of the neck can sometimes make the diagnosis more obvious [6]. An expanding hematoma in this area may affect the airway at different levels as a result of mass effect. Because of anatomical barriers, the bulk of the hematoma could compress the nasopharynx, oropharynx, hypopharynx, or esophagus; therefore, the obstruction could be at the level of the upper airway, cervical trachea, or intrathoracic trachea. This knowledge is the airway obstruction.

Multiple etiological factors could contribute to RH formation and, if no cause is identified, the condition is characterized as a spontaneous RH. Etiologies of RH include infection, cervical spine trauma, great vessel trauma, violent head movements, iatrogenic injury associated with cardiac catheterization or cerebral angiography, parathyroid adenoma hemorrhage, or foreign body ingestion [1]. Anticoagulation states [7-12] or hemorrhagic diathesis predispose to the development of RH in humans [1]. Precipitating factors such as episodes of coughing, sneezing, 
straining and vomiting indirectly contribute to $\mathrm{RH}$ by increasing venous pressure and causing ruptures in the venous system. RH must be differentiated from abscess, arterial aneurysm, malformation or prominence of the vertebral bodies, and adenoiditis [13].

In human medicine, patients with RH secondary to coagulopathy (e.g., hemophilia, hemorrhagic diathesis, or anticoagulant therapy) present with fewer symptoms and, once the diagnosis is made, intubation or tracheotomy is more difficult [1]. In some patients, $12-48 \mathrm{~h}$ of bleeding may precede complaints of respiratory embarrassment; however, an early, seemingly indolent course can suddenly be complicated by airway obstruction. Death can occur following rapid development of respiratory distress from sublingual, retropharyngeal, and parapharyngeal hemorrhages [1]. In the case of $\mathrm{RH}$ in patients on therapeutic anticoagulant therapy, $33 \%$ of patients experienced precipitous airway compromise leading to surgical airway management, and the mortality rate was $10 \%$ [12]. However, in spontaneous $\mathrm{RH}$, there is a reported mortality rate of up to $20 \%$ [14]. In human patients hospitalized for cervical injury, $60 \%$ of $\mathrm{RH}$ cases result from the injury but airway obstruction caused directly by the RH occurs rarely, in only $1.2 \%$ of patients $[15,16]$.

Because a patient's history can be nonspecific, a high index of suspicion is required to diagnose $\mathrm{RH}$. To aid the diagnosis, lateral cervical radiography can be used to measure abnormal thickness of the retropharyngeal tissue. In veterinary medicine, as a rough estimate, the normal distance between the dorsal edge of the cricoid cartilage and the ventral aspect of $\mathrm{C} 2$ is approximately equal to the length of $\mathrm{C} 3$ on a properly positioned lateral radiograph [17]. The authors discuss the first known case of retropharyngeal hematoma in a dog that tested positive for Anaplasma species.

\section{Case presentation}

An 18-month-old, intact female water spaniel $(16 \mathrm{~kg})$ was referred to the Veterinary Teaching Hospital, University of Extremadura, after experiencing weakness, neck pain and progressive paralysis in all limbs that led to lateral recumbency for 7 days. There were no other remarkable findings on physical examination. Complete blood count and serum biochemistry profiles revealed leukocytosis (white blood cell count: $31.5 \times 10^{9} / \mathrm{L}$; reference range, $5.9-16.6 \times 10^{9} / \mathrm{L}$ ); elevated alanine aminotransferase (377 IU/L; reference range, 15-52 IU/L) and alkaline phosphatase (317 IU/L; reference range, $20-70 \mathrm{IU} / \mathrm{L}$ ); and thrombocytopenia $\left(109 \times 10^{9} / \mathrm{L}\right.$; reference range, $\left.117-460 \times 10^{9} / \mathrm{L}\right)$. No coagulation testing was performed.

Based on the history and examination findings, possible differential diagnoses included meningitis, polyradiculoneuritis, polymyositis, and discospondylitis. We anesthetized the dog for a cisternal puncture and cerebrospinal fluid (CSF) tap and encountered no complications during the procedure. Analysis of the cerebrospinal fluid showed elevated protein $(15 \mathrm{~g} / \mathrm{L}$; reference range, $<0.25 \mathrm{~g} / \mathrm{L})$ and neutrophilic pleocytosis (white blood cell count, $5.0 \times 10^{9} /$ $\mathrm{L}$; reference range $<5 \times 10^{6} / \mathrm{L} ; 69 \%$ neutrophils, $39 \%$ lymphocytes). Based on these results, and pending CSF culture, there was a suspicion of bacterial meningitis and the dog was started on antibiotic therapy (sulfamethoxazoletrimethoprim, ${ }^{1} 15 \mathrm{mg} / \mathrm{kg}$ PO q $12 \mathrm{~h}$ and clindamycin, ${ }^{2}$ $10 \mathrm{mg} / \mathrm{kg}$ PO q $12 \mathrm{~h}$ ).

Five hours after extubation, the dog developed stridor and evidence of upper airway obstruction that worsened rapidly. The dog was agitated, tachypneic and cyanotic on room air and was immediately transferred to the operating room to secure the airway. Intubation was attempted via direct visualization with laryngoscopy, but this was difficult because of the size of the hematoma. The epiglottis was not visualized and the correct position of the endotracheal tube was confirmed using capnography. On examination of the oral cavity and oropharynx, there was an ecchymotic swelling of the soft palate. Laryngoscopy confirmed extensive hematoma; pharyngoscopy demonstrated a soft, bulging, violaceous mass involving the lateral and dorsal pharyngeal walls (Fig. 1). A lateral cervical radiograph revealed marked prevertebral soft tissue swelling (Fig. 2). The dog was then transferred to the magnetic resonance imaging (MRI) unit under general anesthesia, and urgent $\mathrm{MRI}^{3}$ of the neck was performed (Fig. 3). MRI revealed a retropharyngeal mass with features consistent with hemorrhage; the trachea was outlined only by the

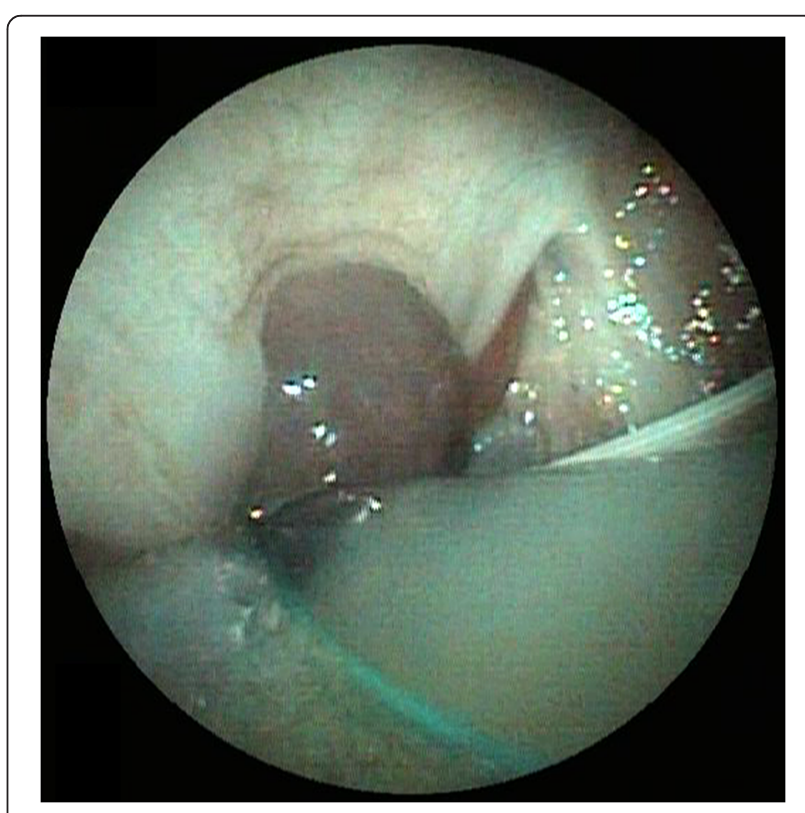

Fig. 1 Pharyngoscopy image demonstrating a soft, bulging, violaceous mass involving lateral and dorsal pharyngeal walls 


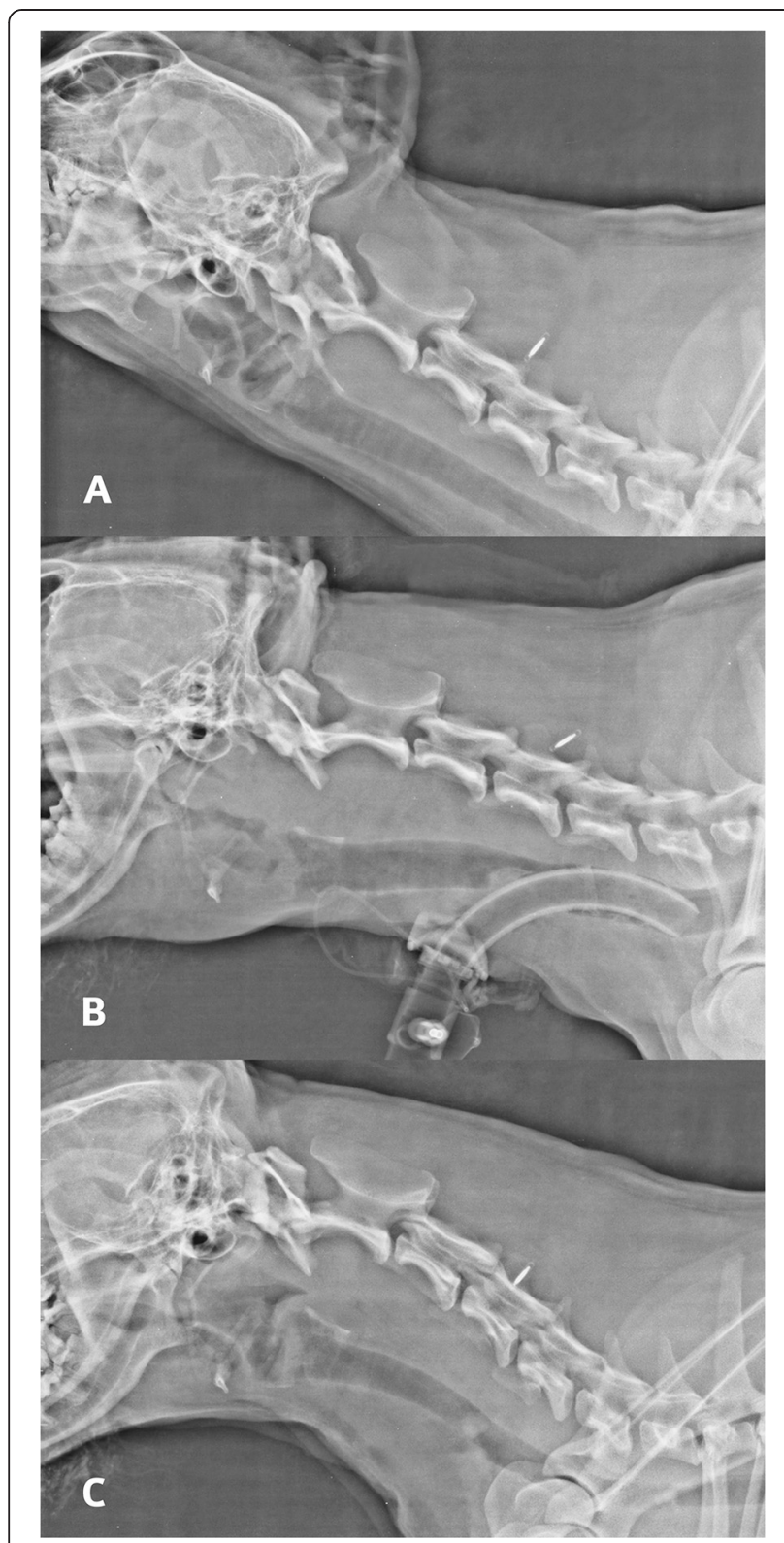

Fig. 2 Lateral cervical spine radiographs showing normal (a) and increased thickness of the prevertebral soft tissue (b, c). a before anesthesia; b during the event; c four days after tracheostomy

endotracheal tube and the mass was causing dorsal compression of the airway.

The severe extent of the upper airway obstruction necessitated surgical tracheostomy, which was performed uneventfully, and aminocaproic acid ${ }^{4}(20 \mathrm{mg} / \mathrm{kg}$ IV), vitamin $\mathrm{K}^{5}$ (2 mg/kg IV), and ethamsylate ${ }^{6}(12.5 \mathrm{mg} / \mathrm{kg} \mathrm{IV)} \mathrm{were}$ administered. Once the dog was stabilized, blood tests were repeated. Hemoglobin was $109 \mathrm{~g} / \mathrm{L}$ from $123 \mathrm{~g} / \mathrm{L}$, platelet count was $36 \times 10^{9} / \mathrm{L}$ from $109 \times 10^{9} / \mathrm{L}$, and clotting study results were in the normal range (thrombin time: $6.4 \mathrm{~s}$, reference range: 6-9 s; partial thromboplastin time: $5.1 \mathrm{~s}$, reference range: $5.1-7.9 \mathrm{~s}$; prothrombin time: $8.7 \mathrm{~s}$, reference

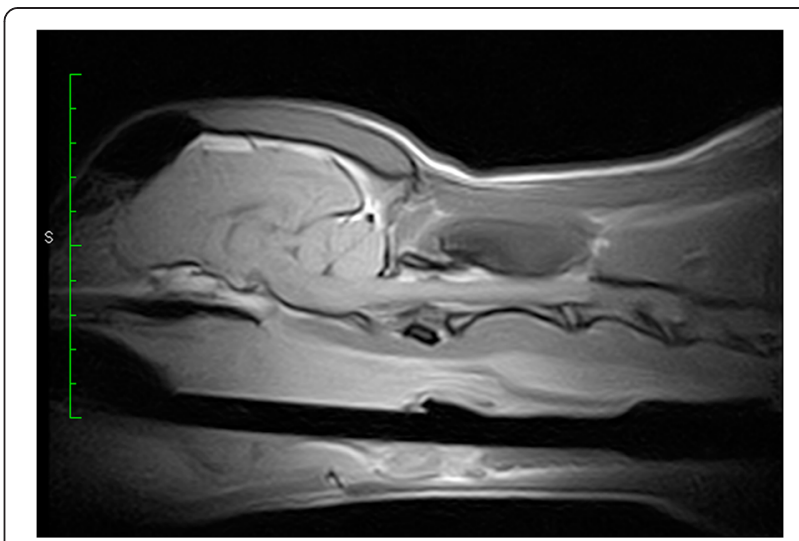

Fig. 3 Sagittal T1 magnetic resonance image showing a high signal prevertebral collection spreading from the nasopharynx to C4

range: 8.6-12.9 s). Despite thrombocytopenia that was just above the range to cause bleeding, buccal mucosal bleeding time was normal (2 $\mathrm{min}$; reference range, 1.7-4.4 $\mathrm{min}$ ); platelet aggregometry was not performed to assess platelet function. Anaplasma and Ehrlichia blood antigen detection $\left(4 \mathrm{DX} \mathrm{X}^{7}\right)$ was performed, and the dog tested positive for Anaplasma spp.; therefore, prednisone ${ }^{8}(2 \mathrm{mg} / \mathrm{kg}$ IV q $12 \mathrm{~h}$ ) and doxycycline ${ }^{9}(10 \mathrm{mg} / \mathrm{kg}$ PO q $24 \mathrm{~h})$ were initiated as treatment for rickettsial meningitis. Over the next $24 \mathrm{~h}$, the platelet count increased to $153 \times 10^{9} / \mathrm{L}$ and the hemoglobin concentration stabilized at $109 \mathrm{~g} / \mathrm{L}$. The tracheostomy tube was removed on the fourth day and normalization of the prevertebral soft tissue was noted on a lateral cervical spine radiograph (Fig. 2). Based on the clinical and radiological findings, a diagnosis of $\mathrm{RH}$ was made. Following negative CSF culture, antibiotic therapy was reduced to doxycycline for one month. Rehabilitation therapy was instituted and in 7 days the dog was able to rise and take a few steps alone. The neurological signs improved with treatment and resolved over the next several months resulting in complete and uneventful recovery.

In this case, a flexible laryngoscope confirmed the diagnosis. The role of flexible pharyngoscopy cannot be overemphasized. Even a small bulging of the posterior wall of the pharynx should alert clinicians and guide the clinical strategy towards a high suspicion of a retropharyngeal space-occupying lesion [18]. Computed tomography is also important to confirm the diagnosis and to assess the extent of the hematoma and its relation to structures in the neck [6]. MRI offers several advantages over computed tomography regarding multiplanar anatomic display and superior soft tissue contrast, allowing more specific diagnoses to be made [19]. MRI not only better depicts the extent of retropharyngeal lesions but, most importantly, is able to identify acute and subacute blood products, thereby affecting both diagnosis and management. MRI is sensitive to blood products in different 
stages of evolution because of their paramagnetic signal properties, which change over time depending on the dominant component (e.g., acute deoxyhemoglobin, subacute intra- or extracellular methemoglobin, and chronic hemicromes).

Spontaneous bleeding generally does not occur until platelet counts fall below $20-50 \times 10^{9} / \mathrm{L}$ unless a concomitant bleeding disorder exists, in which case it can be a lifethreatening event. Thrombocytopenia does not always require intervention, but it certainly warrants monitoring and attention to prevent bleeding episodes [20]. In this case, the dog responded well to treatment with doxycycline and platelet transfusion was not necessary.

In human medicine, most authors report conservative treatment for successful management of $\mathrm{RH}$, and the condition usually resolves within several weeks [6]. Treatment depends on the size, location, and clinical evolution of the patient. In small hematomas, treatment tends to be conservative, and spontaneous resolution occurs [21]. Immediate opening of the hematoma for aspiration appears to increase the risk of infection, which often extends to the mediastinum. If the hematoma is large and re-absorption unlikely, or if the hematoma has extended rapidly, surgical evacuation and controlling the source of bleeding is indicated once the patient has been stabilized [13]. Late complications include a non-resolving hematoma or abscess formation.

There is little consensus in the literature regarding the use of steroids or prophylactic antibiotics in patients with RH [2] and the use of systemic steroids is controversial. Hemorrhage in the upper airway dissects along multiple fascial planes, and this incites an inflammatory reaction that is limited by the use of steroids. Although not of proven benefit, systemic steroids have been used in numerous case reports of upper airway hematomas in people [22, 23].

\section{Conclusions}

The authors report the first known veterinary case of an $\mathrm{RH}$ in a dog. $\mathrm{RH}$ should be considered a rare differential for dogs with underlying coagulopathy that develop upper airway compromise.

\section{Endnotes}

${ }^{1}$ Sulfamethoxazole-trimethoprim: Septrin tablets, 800/ 160 mg, Alcala Farma Laboratories, SL Ctra. M-300, Km 29,920 Alcalá de Henares. 28802 Madrid, Spain

${ }^{2}$ Clindamycin: Dalacin tablets $150 \mathrm{mg}$, Pfizer, SL. Avda. De Europa 20 B, Parque Empresarial La Moraleja. 28108 Alcobendas, Madrid, Spain

${ }^{3}$ Vet-MR Grande, Esaote España SA. Sant Just Desvern, Barcelona, Spain
${ }^{4}$ Aminocaproic acid: Caproamin Fides, injectable, $4 \mathrm{~g}$, Rottapharm Laboratories, SL, Avda. Diagonal, 67-69, 08019, Barcelona, Spain

${ }^{5}$ Vitamin K: Konakion, injectable $10 \mathrm{mg} / \mathrm{ml}$, Roche Farma Laboratories, SA, C/Eucalipto 33, 28016 Madrid, Spain

${ }^{6}$ Ethamsylate: Hemo 141, $125 \mathrm{mg} / \mathrm{ml}$, Esteve SA. Avda. Mare de Déu de Montserrat, 221.08041 Barcelona, Spain ${ }^{7}$ SNAP 4DX; IDEXX Laboratories, Westbrook, ME, USA

${ }^{8}$ Prednisone: Dacortin tablets, $30 \mathrm{mg}$, Merck, SL. Maria de Molina, 40. 28006. Madrid, Spain

${ }^{9}$ Doxycycline: Doxiclat tablets, $100 \mathrm{mg}$, Pierre Fabre Ibérica, SA. C/Ramón Trias Fargas 7-11. 08005 Barcelona, Spain

\section{Abbreviations}

$\mathrm{RH}$ : Retropharyngeal hematoma; MRI: Magnetic resonance imaging.

\section{Competing interests}

The authors declare that they have no competing interests.

\section{Authors' contributions}

All of the authors were involved in the clinical management of the case. LJE was the responsible surgeon, MMC provided the imaging diagnosis, and $\mathrm{W}$ and VLR attended the emergency and stabilized the patient. W drafted the manuscript and provided the figures. $L E, M M C$, and $V L R$ revised the manuscript critically, and provided helpful discussions and final corrections to the manuscript. All authors read and approved the final version of the manuscript.

Received: 12 February 2015 Accepted: 5 October 2015 Published online: 09 October 2015

\section{References}

1. Chin KW, Sercarz JA, Wang MB, Andrews R. Spontaneous cervical hemorrhage with near-complete airway obstruction. Head Neck. 1998;20:350-3.

2. Bloom DC, Haegen T, Keefe MA. Anticoagulation and spontaneous retropharyngeal hematoma. J Emerg Med. 2003;24:389-94.

3. Newton Al. Spontaneous retropharyngeal hematoma: an unusual presentation of thoracic aortic dissection. J Emerg Med. 2006;31:45-8.

4. Wong YK, Novotny GM. Retropharyngeal space - a review of anatomy, pathology, and clinical presentation. J Otolaryngol. 1978;7:528-36.

5. Jones TM, Owen GO, Morar P. Spontaneous retropharyngeal haematoma attributable to Epstein-Barr virus infection. J Laryngol Otol. 1996;110:1075-7.

6. Senthuran S, Lim S, Gunning KE. Life threatening airway obstruction caused by a retropharyngeal haematoma. Anaesthesia. 1999;54:674-8.

7. Baird KH, Fox MS. Severe sublingual and paratracheal hemorrhage in hemophilia with recovery following tracheostomy. J Pediatr. 1943;23:90-4.

8. Owens DE, Calcaterra TC, Aarstad RA. Retropharyngeal haematoma. A complication of therapy with anticoagulants. Arch Otolaryngol. 1975;101:565-8.

9. Rosenbaum L, Thurman P, Krantz SB. Upper airway obstruction as a complication of oral anticoagulation therapy. Arch Intern Med. 1979;139:1151-3.

10. Mackenzie JW, Jellicoe J. Acute upper airway obstruction and spontaneous retropharyngeal haematoma in a patient with polycythaemia rubra vera. Anaesthesia. 1986;41:57-9.

11. Thatcher J, George D. Retropharyngeal haematoma as a cause of acute upper airway obstruction in rheumatoid arthritis. J Rheumatol. 1987;14:1172-3.

12. Sinert $R$, Scalea T. Retropharyngeal and bowel hematomas in an anticoagulated patient. Acad Emerg Med. 1994;1:67-72.

13. Riaño A, Bada MA, Martino R, Etayo A, Castiella UL, Palomero R. Retropharyngeal hematoma. Rev Esp Cirug Oral y Maxilofac. 2004;26:259-62.

14. Paleri V, Maroju RS, Ali MS, Ruckley RW. Spontaneous retro- and parapharyngeal haematoma caused by intrathyroid bleed. J Laryngol Otol. 2002;116:854-8.

15. Penning L. Prevertebral hematoma in cervical spine injury. Am J Roentgenol. 1981;136:553-61.

16. Kuhn JE, Graziano GP. Airway compromise as a result of retropharyngeal hematoma following cervical spine injury. J Spinal Disord. 1991;4:264-9. 
17. O'Brien. Radiographic diagnosis of abdominal disorders in the dog and cat. Philadelphia: W.B. Saunders; 1981.

18. Chiti-Batelli S, Vaz F, Coman S. Traumatic retropharyngeal haematoma in an anticoagulated patient: Case report and proposal for a clinical protocol. Acta Otolaryngol. 2005;125(4):443-5.

19. Muñoz A, Fischbein NJ, de Vergas J, Crespo J, Alvarez-Vicent J. Spontaneous retropharyngeal hematoma: diagnosis by MR imaging. Am J Neuroradiol. 2001:22:1209-11.

20. Drellich S, Tocci $\sqcup$. Thrombocytopenia. In: Silverstein DC, editor. Small animal critical care medicine. St. Louis, Missouri: Saunders Elsevier; 2009. p. 516-8.

21. El Kettani C, Badaoui R, Lesoin FX, Le Gars D, Ossart M. Traumatic retropharyngeal hematoma necessitating emergency intubation. Anesthesiology. 2002;97(6):1645-6.

22. Cohen A, Warman S. Upper ainway obstruction secondary to warfarin-induced sublingual hematoma. Arch Otolaryngol Head Neck Surg. 1989;115:718-20.

23. Jandreau S, Mayer D. Spontaneous bilateral arytenoid hematoma in a patient on warfarin. Am J Emerg Med. 1998;16:674-6.

\section{Submit your next manuscript to BioMed Central and take full advantage of:}

- Convenient online submission

- Thorough peer review

- No space constraints or color figure charges

- Immediate publication on acceptance

- Inclusion in PubMed, CAS, Scopus and Google Scholar

- Research which is freely available for redistribution 